\title{
Editorial
}

Neuro epidemiology

\section{Neuroepidemiology: A Brighter Look for the Future}

Although epidemiology is a relatively young science, it has already played a central role in five recent major achievements in health care: in evidence generation, its rapid critical appraisal, its efficient storage and retrieval, evidence-based medicine, and evidence synthesis [1]. However, mistakenly, many health professionals still believe that epidemiology is only a research about incidence, prevalence and risk factors, thus artificially separating out epidemiology from clinical trials and other clinical research. However, epidemiology is a clinical science aimed at studying disease frequency, distribution and determinants and outcomes in human populations. This definition of epidemiology covers the whole spectrum of clinical research ranging from case reports and ecological studies to randomized clinical trials (RCTs). In this respect, epidemiology should be considered as a fundamental/basic science for all types of clinical research. A failure to recognize it may lead to an increasing gap between researchers applying non-experimental epidemiological study methodologies (e.g., case-control studies, incidence, prevalence, and cohort studies) and researchers applying experimental epidemiological study methodologies (e.g. RCTs, meta-analyses of clinical trials) as well as between epidemiologists and clinicians.

In relation to neurological disorders, the gaps between experimental and non-experimental neuroepidemiology and strategies to address these issues were first discussed during the round table discussion at the 1st International Congress on Neurology and Epidemiology (ICNE) in Munich, Germany in August 2009 [2]. These issues have also been discussed during the 2nd ICNE in Nice, France in November 2012, gathering over 500 participants from 80 countries. These congresses have been organized under the auspices of the journal of Neuroepidemiology, the only international peer-reviewed journal that is entirely devoted to descriptive, analytical and experimental epidemiological studies of neurologic diseases. During these congresses and discussions many delegates indicated a need for establishment of an international association of neuroepidemiology that would systematically address these issues, coordinate and organize ICNE congresses on annual basis and expand the boundaries of traditional clinical neurology by providing new insights regarding the etiology, determinants, distribution, management and prevention of diseases of the nervous system. It was also expected that such an international association would play a coordinating role for various existing national groups and associations of neuroepidemiologists.

In response to these growing demands, we are very pleased to inform you that the International Association of Neurology and Epidemiology (IANE) has been recently established as a charitable, non-profit organisation, with headquarters in Geneva, Switzerland. The Neuroepidemiology journal is now the official journal of the IANE. The main goal of the IANE is to promote epidemiological and clinical studies as well as evidence-based recommendations/guidelines to reduce the burden of neurological disorders in the world through its journal of Neuroepidemiology, ICNE congresses, schools and official website http://www. ianeurology.org. IANE also encourages the exchange of research and professional experience between IANE members. Using a range of activities and through its affiliates, IANE also aims to guarantee and provide the same standard of education and neuroepidemiological information across all countries throughout the world. Recognizing the issues arising from the increased longevity and changing epidemiology of neurological disorders in the 21 st century, IANE will also provide up-todate information and web resources in the field of neuroepidemiology.

IANE offers its members a number of benefits, including online subscription to the KARGER journal Neuroepidemiology, monthly alerts on the content of the Neuroepidemiology journal and reduced registration fee for ICNE congresses. For national neurological or neuroepidemiological group/association affiliated with IANE, IANE offers organising their annual meetings under the auspices of IANE/ICNE. IANE may assist national societies in planning and organising such meetings and providing information on planned International activities in neuroepidemiology. The IANE individual membership is open for all interested health professionals and students for just EUR 55 per year. Affiliated membership for groups and associations will be considered by the Executive Committee of the IANE upon receipt of the expression of interest from the group/association concerned (please see IANE website for details).

We believe this is a very exiting time for all neuroepidemiologists and health professionals dealing with neurological disorders. For the first time we have not only the highly reputable international journal of Neuroepidemiology but also the International Association of Neurology and Epidemiology for all specialists interested in sharing the knowledge of descriptive, analytical and experimental epidemiological studies of neurologic disease, as well as in the development and implementation of evidence-based recommendations for prevention and management of neurological disorders. It is our hope that with these concerted and coherent actions and implementations of evidence-based recommendations into practice, we would be able to reduce the ever-increasing burden of neurological disorders in the world.

Valery Feigin, Editor-in-Chief, Neuroepidemiology

President, International Association of Neurology and Epidemiology

Maurice Giroud, Neuroepidemiology Editorial Representative

Vice-President, International Association of Neurology and

Epidemiology

\section{References}

1 Sackett DL: Clinical epidemiology. What, who, and whither. J Clin Epidemiol 2002;55:1161-1166.

- Feigin V, Kurtzke JF, Korczyn A, Beghi E, Brown A: Bridging the gap between experimental and non-experimental neuroepidemiology, and ultimately - between neuroepidemiological research and practice: round table discussion at the First International Congress on Clinical Neurology and Epidemiology. Neuroepidemiology 2009;33:296-304.

\section{KARGER}

E-Mail karger@karger.com

www.karger.com/ned (c) 2013 S. Karger AG, Base

0251-5350/13/0411-0001\$38.00/0 